\title{
PENGARUH DEWAN KOMISARIS, PROPORSI KOMISARIS INDEPENDEN, TERHADAP KINERJA PERUSAHAAN
}

\author{
Brayen Prastika Dwi Putra \\ Departemen Manajemen, Fakultas Ekonomi dan Bisnis \\ Universitas Airlangga \\ Email: Brayenprastika@gmail.com
}

\begin{abstract}
The purpose of this study is examined the influence of the composition of the board of commissioners toward the performance of companies from three different aspects; return stock market aspects, ROA aspects of accounting, and accounting aspects and market TobinsQ. This research had a sample of 400 financial records from 400 companies with the period of 2010 to 2013. This research used multiple linear regression method. The independent variable is the number of commissioners and the number of independent commissioners. Moderating variables of this research was the size of the company. The dependent variable was the performance of this company with the company RET measurements, ROA, TobinsQ. The results of this study indicated that for RET, the board had significant negative effect, as well as independent directors had not significant positive effect, while the influence of the board of commissioners of the smaller companies were not exhibited significantly negative. The commissioners had not significant positive effect, independent commissioner had significant positive effect, as well as the board of commissioners had not significant negative effect on the performance of smaller companies to ROA. Research on Tobins $Q$, the board has a significant positive effect. Independent commissioner also had positive and significant, and the board of commissioners has no significant negative effect on the performance of smaller companies.
\end{abstract}

Keyword : boardsize, prosentage Non executive director, firm size and firm performance

\section{Pendahuluan}

Pada era pasca perang dingin banyak pelaku bisnis dengan berbagai macam jenis korporasi mulai menjalankan tata kelola perusahaan dengan baik secara terbuka, sistematis dan bertanggung jawab. Hal ini terdorong kebutuhan pasar yang menuntut perusahaan publik menjalankan sistem manajemennya secara baik, transparan, dan auditable, dan maraknya berbagai skandal sistem pelaporan keuangan perusahaan-perusahaan global beberapa tahun yang lalu. Skandal tersebut meliputi perusahaan enron. Fenomena skandal pemalsuan laporan 


\section{Brayen Prastika DwiPutra}

keuangan di Indonesia meliputi PT lippo Tbk, dan PT Kimia Farma Tbk. Karena terdapat fenomena tersebut diperlukan corporate governance yang baik agar memperkuat hubungan antara investor dengan pihak perusahaan, serta transparansina perusahaan dalam mengelola perusahaan. Menurut konsep GCG, perusahaan akan memperoleh nilai perusahaan yang maksimal apabila fungsi dan tugas masing-masing pelaku organisasi bisnis yang modern dapat dipisahkan dengan bentuk: (1) Board of Directors (BOD), dengan mereka bekerja full time dengan tidak boleh merangkap pekerjaan. Mereka mengelola perusahaan melalui berbagai keputusan managerial perusahaan. (2) Board of Commisionners (BOC), meliputi komisaris biasa dan komisaris independen serta berbagai komite yang dibentuknya.

Fungsi utama BOC adalah mengawasi arah kepengurusan dan jalannya perusahaan menurut prinsip GCG. Agar fungsi dewan komisaris berjalan dengan baik, maka perlu dipastikan segala keputusan tentang kemajuan perusahaan tidak memihak kepentingan board of director sebagai agen atau bias dengan kepentingan pemilik. Hal ini yang sering terjadi di dalam perusahaan dalam mencapai tujuannya, yakni terjadinya agency problem.

\section{Landasan Teori}

\section{Teori Keagenan}

Teori keagenan adalah suatu kontrak antara prinsipal dengan agen. Weston dan Brigham (1993:17) menjelaskan bahwa hubungan keagenan yang terjadi ketika seseorang (principal) menyewa orang lain (agent) yang kemudian diberikan wewenang dalam mengambil keputusan. Sering terjadinya asymetri informasi antara pemegang saham dengan manajer, hal ini terjadi karena adanya pemisah antara pemilik dengan manajer atau yang mengendalikan, oleh karena itu pemegang saham selaku pemilik harus selalu memonitor tindakan yang dilakukan oleh manajer agar manajer selalu bertindak sesuai dengan keinginan pemilik. Hal senada juga diungkapkan Jensen and Meckling (1976) yaitu hubungan keagenan merupakan suatu kontrak antara principal yang menyewa orang lain atau agent untuk melaksanakan jasa dan mengambil keputusan yang telah didelegasikan kepadanya. Cara yang dilakukan untuk memonitor manajer adalah dengan adanya corporate governance. Prinsip-prinsip corporate governance adalah dengan transparancy accountabillity, responsibility,indepedency, fairness.

\section{Ukuran Dewan Komisaris (Board Size)}

Pengawasan yang tidak efektif dari dewan komisaris akan terjadi masalah keagenan yakni dengan makin banyaknya dewan komisaris maka perusahaan ini akan mengalami 71 
kesulitan dalam melakukan proses komunikasi, koordinasi tugas tugas serta efektifitas dalam pembuatan keputusan. Karena semakin besar jumlah dewan komisaris maka akan semakin sulit, serta mahal dan memakan waktu lama baik dalam hal komunikasi, maupun koordinasi dalam pembuatan keputusan (Yermack 1996, jensen 1993). Yermack (1996) juga mengungkapkan semakin banyaknya personel yang menjadi dewan komisaris dapat berakibat pada buruknya kinerja yang dimiliki perusahaan. Conyon dan Peck (1998) menjelaskan bahwa terdapat hubungan negative antara ROE dengan jumlah dewan komisaris. De Andres et al (2005) mengatakan hal yang sama didalam penelitiannya terdapat hubungan negatif antara nilai perusahaan dengan jumlah dewan komisaris. Berbeda dengan yang diteliti oleh Dalton (1999) menjelaskan bahwa semakin tinggi dewan komisaris di dalam perusahaan maka semakin baik. Karena semakain banyak yang memonitor tingkah laku manajemen sehingga akan selalu bertindak sesuai dengan keinginan pemegang saham.

BRDSIZE $=\sum$ anggota dewan komisaris

\section{Firm Size}

Ukuran perusahaan menjadi variabel moderasi antara variabel board size dengan kinerja perusahaan. Jadi untuk variabel ini meneliti pengaruh dari dewan komisaris dengan moderasi fim size. Terdapat pengaruh yang berbeda antara perusahaan besar dan perusahaan kecil. Finklestein dan hambrick (1996) menjelaskan bahwa struktur dewan didalam perusahaan yang lebih kecil mempunyai fungsi untuk mengatur strategi, jadi dari perspektif ini dampak dari besarnya struktur dewan tidak berbahaya untuk perusahaan yang lebih kecil. Selain itu faktor lingkungan informasi yang berbeda antara perusahaan besar dan kecil. O'Connel (1995) menjelaskan bahwa lingkungan informasi untuk perusahaan besar dan kecil sangat berbeda. Perusahaan besar bekerja dengan lingkungan informasi yang besar, pengawasan dari berbagai media dan masyarakat umum, hal ini berbeda dengan perusahaan besar yang bekerja dengan lingkungan informasi yang terbatas, sehingga peran dari dewan komisaris akan lebih baik untuk perusahaan yang lebih kecil. Variabel ini menggunakan dummy variabel nilai 1 untuk perusahaan kecil dan 0 perusahaan besar.

\section{Komisaris Independen (NED)}

Jensen dan Meckling (1976) menjelaskan bahwa semakin banyak pemonitor akan semakin baik karena terjadinya konflik semakin rendah dan akhirnya menurunkan agency cost. Menurut stiles dan taylor (2001) menjelaskan bahwa tingginya proporsi untuk komisaris 


\section{Brayen Prastika DwiPutra}

independen akan meningkatkan kinerja keuangan perusahaan. Hal ini senada dengan yang diungkapkan oleh yawson (2006) bahwa ketika tingginya proporsi untuk komisaris eksternal maka komisaris eksternal akan memberikan sanksi yang tegas terhadap pekerja yang mengalami penurunan kinerja. Hal ini menjelaskan bahwa komisaris independen berpikir lebih obyektif dibanding dewan komisaris dan direksi. Pengawasan komisaris terhadap manajemen umumnya tidak efektif dikarenakan proses pemilihan dewan komisaris yang kurang demokratis, kandidat dewan komisaris sering dipilih sendiri oleh manajemen sehingga setelah terpilih tidak berani mengkritik kebijakan manajemen. Dalam menjamin terciptanya GCG yang baik maka komisaris independen diharuskan mempunyai kredibilitas, profesional, integritas yang baik. Komisaris independen memikul tanggung jawab untuk mendorong secara proaktif agar komisaris dalam melaksanakan tugasnya sebagai pengawas dan penasihat direksi dapat memastikan perusahaan memiliki strategi bisnis yang efektif, memastikan perusahaan mematuhi hukum perundangan yang berlaku maupun nilai nilai yang ditetapkan di perusahaan, sehingga perusahaan perusahaan memiliki corporate governance yang baik.Dapat disimpulkan bahwa semakin tinggi proporsi komisaris independen semakin tinggi pula kepemilikan asing dikarenakan investor asing lebih percaya pada perusahaan yang memiliki lebih banyak komisaris independen

Hipotesis 3. Proporsi Dewan Komisaris mempunyai pengaruh positif terhadap kinerja perusahaan.

\section{Kinerja Perusahaan}

Menurut menteri keuangan Rl berdasarkan keputusan No 740/kmko/1989 tanggal 30 juni 1989, menyatakan bahwa kinerja adalah prestasi perusahaan dalam suatu periode yang mencerminkan tingkat kesehatan dari perusahaan tersebut. Kinerja perusahaan merupakan alat ukur keberhasilan manajer dalam menjalankan perusahaan. Informasi tersebut sangat berguna bagi pihak pihak yang berkepentingan didalam perusahaan seperti pemerintah, masyarakat, kreditur dan pemegang saham.

Bagi pemegang saham informasi mengenai kinerja perusahaan untuk mengetahui apakah pengelolaan perusahaan yang dilakukan oleh manajer sudah efektif dan efisien atau belum. Serta apakah sudah sesuai dengan tujuan yang diharapkan atau tidak. Oleh karena itu pengukuran kinerja perusahaan menggunakan rumus Tobin's. Pengukuran Tobin's Q biasanya 


\section{Jurnal Manajemen Teori dan Terapan \\ Tahun 8. No. 2, Agustus 2015}

disebut FINANCIAL $Q$ merupakan pencerminan gabungan pengukuran 2 elemen yakni pengukuran pasar dengan pengukuran akuntansi. Dua penilaian tersebut market value dari saham beredar yang mengukur penilaian pasar terhadap aset perusahaan dan debt yang diartikan sebagai biaya dari aset perusahaan. Debt dalam penilaian Tobin's Q adalah hutang jangka panjang dan hutang jangka pendek. Tingginya nilai FINANCIAL Q mengindikasikan penggunaan aset lebih efisien. (Enriques and Volphin, 2007). O'Connel (2010) memberikan rumus untuk menghitung Tobins $Q$ adalah sebagai beriku†

TOBIN'S Q $=\frac{\text { MVEit }+ \text { DEBTit }}{\text { TAit }}$

Keterangan :

MVEit = Market value of equity perusahaan i pada akhir tahun ke $t$, yang diperoleh dari harga penutupan saham diakhir tahun x jumlah lembar saham beredar.

DEBT $\quad=$ Total debt perusahaan i pada akhir tahun $\dagger$

TA $\quad=$ Total asset perusahaan i pada akhir tahun $\dagger$

Ukuran lain yang digunakan untuk mengukur kinerja perusahaan adalah menggunakan RET. RET merupakan pengukuran berdasarkan elemen pasar. RET dapat dihitung dengan melihat perubahan harga saham pada awal periode dan akhir periode perusahaan ditambah deviden, sehingga ketika kinerja perusahaan meningkat akan tercermin dengan naiknya harga saham perusahaan pada akhir periode. RET ini adalah tingkat pengembalian yang diterima investor pada saat penerimaan pembayaran sampai akhir periode kepemilikan..

RET $=(($ Pt- $(\mathrm{Pt}-1)+$ dividen $/(\mathrm{Pt}-1)$

Keterangan $=$

RET : Return Saham

P† : Harga closing price pada tahun †

Pt-1 : Harga closing price pada tahun t-1 


\section{Brayen Prastika DwiPutra}

Ukuran terakhir yang dipakai adalah ROA. ROA merupakan pengukuran dari aspek akuntansi. Healy dan Wahlen (1999) menjelaskan bahwa pengukuran akuntansi sangat rentan terhadap manipulasi dan kecenderungan akuntan untuk bersikap konservatisme berarti berita buruk lebih cepat tersebar dibanding berita baik. Pengukuran akuntansi ROA merupakan pencerminan dari kinerja perusahaan. Sudana (2011:22) menyatakan bahwa ROA menunjukkan kemampuan perusahaan dengan menggunakan seluruh aset yang dimiliki untuk menghasilkan laba setelah pajak. Rasio ini penting bagi pihak manajemen perusahaan untuk mengevaluasi efektifitas dan efisiensi manajemen perusahaan dalam mengelola seluruh aset perusahaan. Semakin ROA menunjukkan semakin efisien penggunaan aset perusahaan. Rumus yang dipakai adalah sebagai berikut :

$\mathrm{ROA}=\frac{\text { EARNING AFTER TAX }}{\text { TOTAL ASSETS }}$

Dari landasan teori diatas, maka hipotesis penelitian adalah :

$\mathrm{HI}$ : Terdapat pengaruh negatif antara struktur dewan komisaris dengan kinerja perusahaan

H2 : Terdapat pengaruh positf antara struktur dewan komisaris terhadap kinerja perusahaan dengan moderasi firm size

H3 : Terdapat pengaruh positif antara proporsi jumlah komisaris independen terhadap kinerja perusahaan

Model analisis :

\section{RETit=}

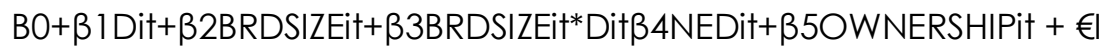

Tobins $Q=$

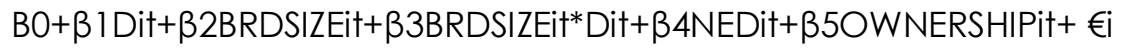

\section{ROAit $=$}

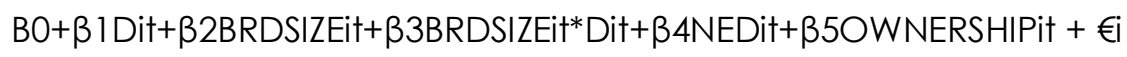

Keterangan :

75 


\begin{tabular}{|c|c|}
\hline Dit & : Variabel dummy untuk dewan komisaris \\
\hline BRDSIZEit & $\begin{array}{l}\text { : Jumlah dewan komisaris untuk perusahaan besar pada } \\
\text { tahun } \dagger\end{array}$ \\
\hline BRDSIZE†*Dit & $\begin{array}{l}\text { : Jumlah dewan komisaris untuk perusahaan yang lebih kecil pada } \\
\text { tahun ke } \dagger\end{array}$ \\
\hline NEDit & : Proporsi komisaris independen \\
\hline OWNERSHIPit & $\begin{array}{l}\text { : Variabel Kontrol, Proporsi kepemilikan saham oleh } \\
\text { manajemen maupun dewan direksi dan komisaris }\end{array}$ \\
\hline RETi† & : Return Saham, pengukuran berdasarkan aspek pasar \\
\hline FINANCIAL Qi† & $\begin{array}{l}\text { : Pengukuran aspek gabungan antara pasar dan akuntansi } \\
\text { pencerminan dari Tobins } Q\end{array}$ \\
\hline ROAit & : Pengukuran untuk aspek akuntansi \\
\hline$\beta 1 \beta 2 \beta 3 \beta 4 \beta 5 \beta 6$ & : Koefisien Regresi \\
\hline$€$ & : Kesalahan Residual \\
\hline
\end{tabular}

\section{Kerangka Berpikir}

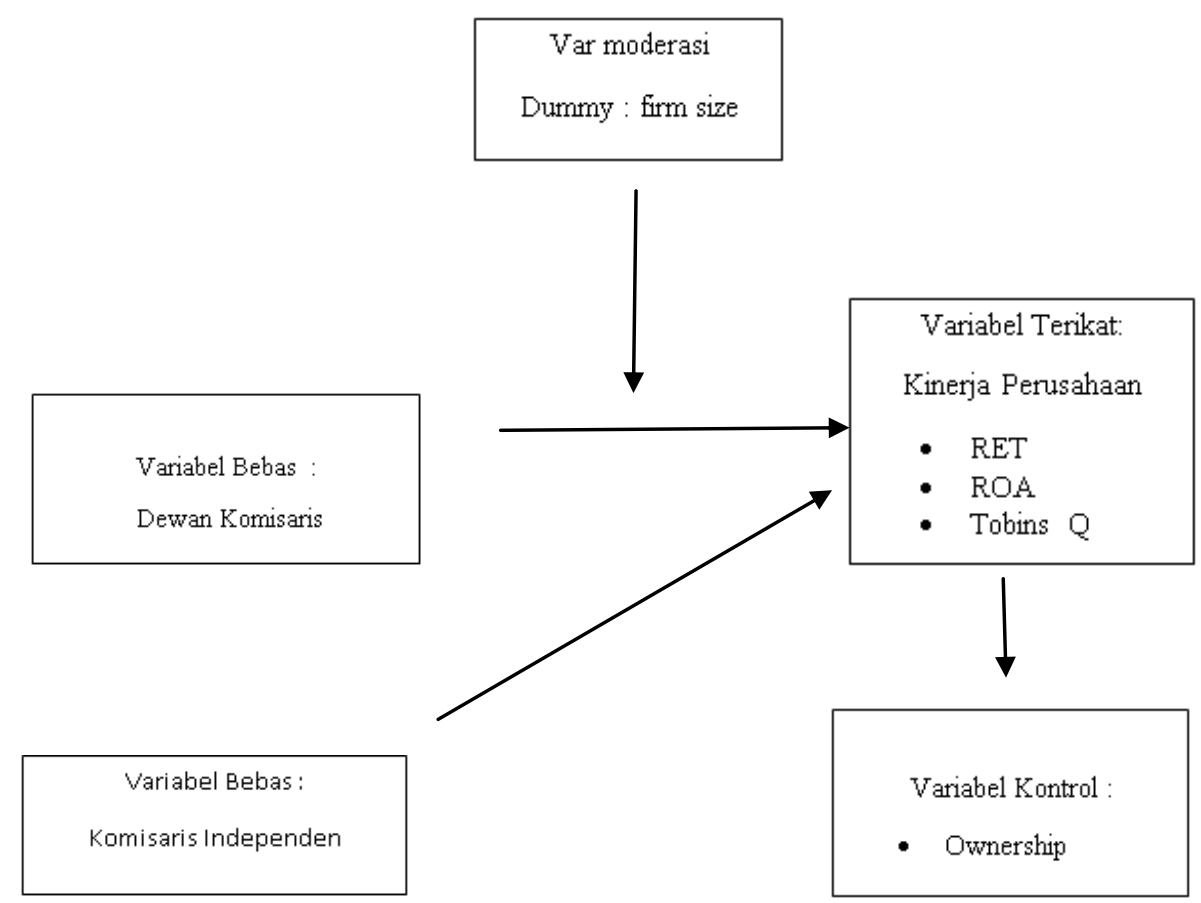




\section{Brayen Prastika DwiPutra}

\section{Metode Penelitian}

Metode pengumpulan sampel

Sampel ditentukan dengan metode purpose sampling untuk mencapai batasan batasan atau tujuan tertentu yang diharapkan. Kriterianya adalah sebagai berikut :

1. Perusahaan manufaktur yang terdaftar di Bursa Efek selama periode 2010-2013

2. Perusahaaan memiliki informasi tentang komisaris independen, dewan komisaris, serta informasi tentang kepemilikan saham perusahaan.

3. Perusahaan mempunyai data laporan keuangan, maupun tahunan yang lengkap mulai tahun 2010-2013

\section{Pengukuran dan definisi oprasional variabel}

Boardsize adalah jumlah dewan komisaris yang terdapat di suatu perusahaan. Ukuran untuk variabel ini menggunakan total dewan komisaris

Firm size adalah variabel moderasi, yang meneliti antara pengaruh dewan komisaris terhadap kinerja perusahaan dengan moderasi firm size. Variabel ini menggunakan dummy dan nilai 0 untuk perusahaan besar dan 1 untuk perusahaan kecil. Sebelum di dummy kan dihitung kapitalisasi perusahaan sampel kemudian dicari median untuk mendapatkan batas nilai tengah.

Komisaris Independen (NED)adalah proporsi komisaris independen didalam suatu perusahaan. Proporsi komisaris independen sangat penting untuk mempengaruhi kinerja perusahaan, dikarenakan komisaris independen dapat berpikiran obyektif tanpa mempunyai kepentingan dengan berbagai pihak.

\section{Hasil dan Pembahasan}

Tabel 1

Hasil regresi variabel dependen RET

\begin{tabular}{|c|c|c|c|c|c|c|c|}
\hline \multirow[b]{2}{*}{ Model } & \multicolumn{2}{|c|}{$\begin{array}{l}\text { Unstandardized } \\
\text { Coefficients }\end{array}$} & \multirow{2}{*}{$\begin{array}{l}\text { Standardized } \\
\text { Coefficients } \\
\text { Beta }\end{array}$} & \multirow[b]{2}{*}{$\mathrm{t}$} & \multirow[b]{2}{*}{ Sig. } & \multicolumn{2}{|c|}{ Collinearity Statistics } \\
\hline & B & Std. Error & & & & Tolerance & VIF \\
\hline (Constant) & .564 & .171 & & 3.296 & .001 & & \\
\hline
\end{tabular}


Jurnal Manajemen Teori dan Terapan

Tahun 8. No. 2, Agustus 2015

\begin{tabular}{|l|l|l|l|l|l|l|l|}
\hline BRDSIZE & -.058 & .026 & -.150 & -2.207 & .028 & .535 & 1.868 \\
NED & .026 & .315 & .004 & .083 & .934 & .931 & 1.074 \\
Control:Owner & .002 & .002 & .059 & 1.161 & .247 & .950 & 1.053 \\
dhip & & & & & & & \\
Dummy & -.221 & .182 & -.188 & -1.216 & .225 & .103 & 9.751 \\
brdsize_D & -.002 & .044 & -.007 & -.051 & .960 & .117 & 8.522 \\
\hline
\end{tabular}

Tabel 2

Hasil regresi variabel dependen ROA

\begin{tabular}{|c|c|c|c|c|c|c|c|c|}
\hline & & \multicolumn{2}{|c|}{$\begin{array}{l}\text { Unstandardized } \\
\text { Coefficients } \\
\end{array}$} & \multirow{2}{*}{\begin{tabular}{|l} 
Standardized \\
Coefficients
\end{tabular}} & \multirow[b]{2}{*}{$t$} & \multirow[b]{2}{*}{ Sig. } & \multicolumn{2}{|l|}{$\begin{array}{l}\text { Collinearity } \\
\text { Statistics }\end{array}$} \\
\hline \multicolumn{2}{|c|}{ Model } & B & Std. Error & & & & Tolerance & VIF \\
\hline \multirow[t]{6}{*}{1} & (Constant) & .027 & .030 & & .896 & .371 & & \\
\hline & BRDSIZE & .000 & .004 & .005 & .073 & .942 & .540 & 1.853 \\
\hline & NED & .114 & .055 & .106 & 2.058 & .040 & .930 & 1.075 \\
\hline & $\begin{array}{l}\text { Control:Ownerdhi } \\
\text { p }\end{array}$ & .000 & .000 & -.069 & -1.364 & .173 & .949 & 1.054 \\
\hline & Dummy & .007 & .032 & .032 & .206 & .837 & .104 & 9.646 \\
\hline & brdsize_D & $\begin{array}{l}-.010 \\
\end{array}$ & .008 & -.183 & -1.275 & .203 & .119 & 8.416 \\
\hline
\end{tabular}

Tabel 3

Hasil regresi variabel dependen tobins $Q$

\begin{tabular}{|c|c|c|c|c|c|c|c|c|}
\hline & & \multicolumn{2}{|c|}{$\begin{array}{l}\text { Unstandardized } \\
\text { Coefficients }\end{array}$} & \multirow{2}{*}{\begin{tabular}{|l} 
Standardized \\
Coefficients \\
Beta \\
\end{tabular}} & \multirow[b]{2}{*}{$t$} & \multirow[b]{2}{*}{ Sig. } & \multicolumn{2}{|c|}{ Collinearity Statistics } \\
\hline \multicolumn{2}{|c|}{ Model } & $B$ & Std. Error & & & & Tolerance & VIF \\
\hline \multirow[t]{4}{*}{1} & (Constant) & .948 & .147 & & 6.459 & .000 & & \\
\hline & BRDSIZE & .054 & .022 & .151 & 2.431 & .015 & .530 & 1.886 \\
\hline & NED & .543 & .271 & .094 & 2.003 & .046 & .929 & 1.077 \\
\hline & $\begin{array}{l}\text { Control:Ownershi } \\
\text { p }\end{array}$ & .002 & .002 & .070 & 1.510 & .132 & .953 & 1.049 \\
\hline
\end{tabular}




\section{Brayen Prastika DwiPutra}

\begin{tabular}{|l|l|l|l|l|l|l|l|}
\hline Dummy & -.217 & .155 & -.197 & -1.398 & .163 & .103 & 9.688 \\
brdsize_D & -.047 & .037 & -.167 & -1.271 & .204 & .119 & 8.423 \\
\hline
\end{tabular}

\section{Pembahasan}

Hasil pembahasan pada model regresi RET ini menunjukan bahwa boardsize mempunyai pengaruh negatif signifikan terhadap kinerja perusahaan. Semakin besar ukuran dewan komisaris di dalam suatu perusahaan, maka akan menurunkan kinerja perusahaan secara tidak langsung. Hasil penelitian ini sesuai dengan yang dijelaskan oleh Jensen dan Meckling (1993) yakni semakin banyak dewan komisaris di dalam perusahaan maka akan semakin buruk kinerja perusahaan karena dewan komisaris akan kesulitan dalam menjalankan perannya diantaranya kesulitan dalam koordinasi dan komunikasi antar dewan komisaris. Turunnya kinerja perusahaan akan menurunkan harga saham perusahaan dibandingkan dengan periode sebelumnya, sehingga minat investor untuk berinvestasi pada perusahaan tersebut akan berkurang. Hal ini sesuai dengan penelitian Wijaya (2007) yang menjelaskan bahwa pada dasarnya harga saham salah satunya dipengaruhi oleh permintaan dan penawaran saham.

Hasil penelitian pengaruh dewan komisaris terhadap kinerja perusahaan dengan pengukuran variabel dependen ROA mempunyai pengaruh positif tidak signifikan. Hal ini sesuai dengan penelitian yang dilakukan oleh Dalton et al (1999) yakni semakin banyak jumlah dewan komisaris maka semakin ketat pengawasan dari dewan komisaris terhadap dewan direksi dan manajerial. Pengawasan tersebut akan meningkatkan kinerja perusahaan. Jadi ketika kinerja perusahaan naik akan tercermin dari naiknya ROA, karena ROA merupakan salah satu rasio profitabilitas perusahaan (indikator naik atau turunnya kinerja perusahaan). Hal ini sesuai dengan penelitian yang dilakukan Afnan (2014) yakni terdapat pengaruh positif signifikan antara boardsize dengan ROA perusahaan. Pengertian ROA adalah rasio yang melihat seberapa efisien dan efektif perusahaan dalam mengelola aset perusahaan untuk menjadikan laba. Semakin besar ROA, maka semakin efisien penggunaan aktiva perusahaan (Made Sudana, 2011).

Pada penelitian ini dewan komisaris berpengaruh positif signifikan terhadap kinerja perusahaan dengan pengukuran Tobins $Q$. Hal ini sesuai dengan penelitian yang dilakukan Dalton et al (1999) dalam O connel (2010) yang menjelaskan bahwa terdapat pengaruh positif antara dewan komisaris terhadap kinerja perusahaan. Hal ini sama seperti penelitian terhadap ROA sebelumnya yakni semakin banyak jumlah dewan komisaris dalam suatu perusahaan, maka pengawasan terhadap manajemen dan dewan direksi akan lebih ketat sehingga 


\section{Jurnal Manajemen Teori dan Terapan}

Tahun 8. No. 2, Agustus 2015

manajemen dan dewan direksi senantiasa mengikuti kehendak pemegang saham. Semakin banyaknya dewan komisaris maka masukan terhadap dewan direksi juga semakin banyak sehingga opsi yang diperoleh dewan direksi semakin banyak. Oleh karena itu penambahan jumlah dewan komisaris akan menaikkan kinerja perusahaan.

Hasil penelitian dengan variabel dependen RET menunjukkan bahwa komisaris independen mempunyai pengaruh positif tidak signifikan terhadap kinerja perusahaan dengan pengukuran return saham. Hal ini sesuai hipotesis yakni semakin besar jumlah dewan komisaris independen, maka semakin baik dalam mengawasi dan mengontrol tindakan tindakan dewan direktur eksekutif. Jensen dan Meckling (1976) menjelaskan bahwa komisaris independen diperlukan untuk mengawasi dan mengontrol segala tindakan oportunistik dari dewan direksi. Dengan semakin berfungsinya peran dari dewan komisaris dalam mengawasi manajer maka kepercayaan investor akan semakin besar terhadap suatu perusahaan. Jadi semakin tinggi proporsi dewan komisaris independen akan meningkatkan kinerja perusahaan sehingga akan menaikkan harga saham perusahaan dan akan meningkatkan return saham untuk investor.

Hasil penelitian ini menunjukan bahwa komisaris independen mempunyai pengaruf positif yang signifikan terhadap kinerja perusahaan dengan pengukuran ROA. Ketika jumlah dari dewan komisaris independen ditambah maka kinerja perusahaan akan naik. Hal ini sesuai dengan penelitian yang dilakukan Daily dan Dalton (1999) dalam penelitian tersebut ditemukan bahwa lebih banyak direktur non executive (NED) yang independen disuatu perusahaan akan meningkatkan kinerja perusahaan. Fungsi dari dewan komisaris independen yakni merupakan dewan pengawas, jadi ketika proporsi NED tinggi maka fungsi pengawasan akan lebih ketat terhadap manajemen, sehingga manajemen akan selalu bertindak untuk kepentingan pemegang saham. Ketika proporsi untuk dewan komisaris independen ditambah maka akan menaikkan kinerja perusahaan. Meningkatnya kinerja perusahaan akan menaikkan ROA tersebut.

Penelitian ini mempunyai hasil sesuai hipotesis yakni komisaris independen berpengaruh positif signifikan terhadap kinerja perusahaan. Hal ini terkait dengan fungsi dari komisaris independen, yakni melakukan fungsi pengawasan, evaluasi, dan pemecatan terhadap manajer puncak (KNKG, 2006). Serta peranan komisaris independen pada perusahaan adalah obyektif yakni tidak terikat oleh kepentingan dan pihak manapun. Jika proporsi komisaris independen ditambah didalam komposisi dewan komisaris maka pengawasan terhadap manajemen dan dewan direksi serta laporan keuangan perusahaan juga akan semakin keta† 


\section{Brayen Prastika DwiPutra}

dan obyektif. Sehingga manajemen akan selalu bertindak sesuai tujuan perusahaan. Ketika proporsi dewan komisaris ditambah maka akan menaikkan kinerja perusahaan. Ketika kinerja perusahaan naik, maka penilaian pasar terhadap aktiva perusahaan juga akan naik. Hal ini akan menarik keinginan investor untuk memiliki saham tersebut. Hal ini sesuai dengan penelitian yang dilakukan O'Connell dan Cramer (2010) yang menjelaskan bahwa proporsi komisaris independen berpengaruh positif terhadap kinerja perusahaan dengan pengukuran RET, ROA, Tobins $Q$.

Dewan komisaris dengan moderasi firm size memiliki pengaruh yang tidak signifikan terhadap kinerja perusahaan. Hal ini sama seperti yang sebelumnya yakni pengaruh dewan komisaris terhadap kinerja perusahaan dengan pengukuran return saham yang mempunyai hasil negatif. Hal ini terkait fungsi dari dewan komisaris semakin banyak jumlah dewan komisaris didalam perusahaan maka akan menimbulkan kesulitan dalam berkomunikasi dan akan menurunkan kinerja perusahaan. Perusahaan kecil mempunyai "span of control'sempit sehingga masalah keagenan antar individu jarang terjadi. Sedangkan perusahaan besar mempunyai span of control luas menyebabkan masalah keagenan antar individu dalam perusahaan sering terjadi. Luasnya "span of control " pada perusahaan besar berdampak jarang bertemunya pemilik dan pihak manajemen. Hal ini mengakibatkan kurangnya interaksi antara pemilik dan pihak manajemen, sehingga pemilik tidak dapat mengawasi tindakan manajemen dan menyebabkan manajemen dapat lebih leluasa bertindak sesuai kemakmurannya sendiri. Oleh karena itu semakin besar jumlah dewan komisaris diperusahaan perusahaan maka akan menurunkan kinerja perusahaan. Turunnya kinerja perusahaan akan tercermin pada penurunan ROA perusahaan. Penurunan kinerja perusahaan juga menyebabkan hak pemegang saham yakni dividen juga akan cenderung turun. Harga saham perusahaan juga akan turun dikarenakan daya tarik investor terhadap perusahaan tersebut turun. Ketika harga saham turun maka akan mengurangi return bagi investor.

Dalam jangka panjang jika perusahaan terus mengalami penurunan kinerja, maka reaksi pasar juga akan buruk. Perusahaan yang mengalami penurunan kinerja akan dinilai buruk dan tidak menarik bagi investor. Hal ini sama dengan penelitian de Andres et al (2005) yang menjelaskan tidak ada hubungan antara ukuran perusahaan dengan kinerja perusahaan dan dewan komisaris dan penelitian yang dilakukan Sundragen dan Wells (1998) yang menunjukan bahwa terdapat hubungan negatif antara dewan komisaris terhadap nilai perusahaan untuk perusahaan besar

SIMPULAN DAN SARAN

81 


\section{Jurnal Manajemen Teori dan Terapan \\ Tahun 8. No. 2, Agustus 2015}

Simpulan

Berdasarkan dari hasil penelitian dan analisis, maka dapat diambil kesimpulan sebagai berikut:

1. Boardsize memiliki pengaruh positif tidak signifkan terhadap kinerja perusahaan return saham sedangkan berpengaruh positif tidak signifikan terhadap ROA, dan terhadap TobinsQ mempunyai pengaruh positif dan signifikan. Untuk RET (return saham) kurang cocok untuk dijadikan pengukuran yang memproksikan kinerja perusahaan untuk aspek pasar.

2. Boardsize dengan moderasi firm size memiliki pengaruh positif tidak signifikan terhadap kinerja perusahaan return saham, ROA, dan Tobins $Q$

3. NED memiliki pengaruh positif tidak signifkan terhadap alat ukur kinerja perusahaan return saham, sedangkan terhadap ROA dan Tobins $Q$ memiliki pengaruh positif signifikan

Saran

Berdasarkan penelitian yang telah dilakukan, maka penulis dapat memberikan saran atau masukan sebagai berikut:

1. Pada penelitian selanjutnya dapat menambah variabel terikat lainnya selain variabel yang telah disebutkan.

2. Peneliti selanjutnya hendaklah menambah jenis perusahaan, tidak hanya meneliti perusahaan manufaktur, melainkan perbankan dan sebagainya.

\section{DAFTAR REFERENSI}

Afnan A. 2014. Pengaruh Ukuran Dewan Komisaris dan Proporsi Komisaris Independen terhadap Kinerja Keuangan dengan Manajemen Laba sebagai variabel intervening.

Brigham, Eugenie \& Houston. 2006. Fundamental of Financial Management. Penerbit Salemba empat

Brigham, Eugenie \& Houston. 2010. Fundamental of Financial Management. Edisi 10. Penerbit Salemba empat. 


\section{Brayen Prastika DwiPutra}

Conyon, M.J and Peck.1998. Board Size and Corporate Performance: Evidence from European Countries. European Journal of Finance(4). 291-304

Dalton, D., Daily, C., Johnson, J. and Ellstrand, A. 1999. Number of directors and financial performance : A meta analysis. Academy of Management Journal. 42(6), 674-686

de Andres, P., Azofra, V. and Lopez, F. 2005. Corporate Governance in OECD Countries: Size, composition, function, and effectiveness. Corporate Governance: An International Review 13 (2), 197-210

Denis, D. K. and McConnell, J. J. 2003 International corporate governance. Journal of Financial and Quantitative Analysis 38(1), 1-36.

Eisenberg, 1998. Larger board size and decreasing firm value in small firm. Hal 35-54

Faccio, M. and Lasfer, M. A. 1999. Managerial Ownership, board structure, and firm value: The UK evidence. Cass Business School Research Paper. Available at SSRN: www.ssrn.com

Forum for Corporate Governance in Indonesia. 2001. Tata Kelola Perusahaan. Seri Tata Kelola Perusahaan, jilid II. Edisi ke 2. Jakarta. 2001.

Forum for Corporate Governance in Indonesia. 2001. Peranan Dewan Komisaris dan komite Audit dalam pelaksanaan Corporate Governance. Seri Tata Kelola Perusahaan, jilid II. Edisi ke 2. Jakarta

Finkelstein, S. and Hambrick, D. C. 1996. Strategic leadership: Top executives and their effects on organizations. West, Minneapolis. St.Paul.

Himmelberg, C., Hubbard, R. and Palia, D. 1999. Understanding the determinant managerial ownership and the linked between ownership and performance. Journal of Financial Economics $53,353-384$

Ghozali. 2006. Aplikasi Analisis Multivariate dengan program SPSS. Cetakan IV. Semarang: Badan Penerbit Universitas Diponegoro.

Isshaq, Zangina. 2009. Corporate Governance governance, ownership structure, cash holding, and firm value on the Ghana stock Exchange. The Journal of Risk Finance, vol. 10 No. 5, pp. 488499. www.emeraldinsight.co.id

Jensen, M. 1993. The modern industrial revolution, exit and the failure of internal control systems. Journal of Finance 48, 831-880. 


\section{Jurnal Manajemen Teori dan Terapan Tahun 8. No. 2, Agustus 2015}

Jensen, M. and Meckling, W. 1976. Theory of the firm: Managerial behaviour, agency costs and ownership structure. Journal of Financial Economics 3, 305-350

KNKG. 2006. Pedoman umum corporate governance di Indonesia. www.bappepam.go.id

O'Connel, V dan Nicole Crammer. 2010. The relationship between firm performance and board characteristics in Ireland. European Management Journal. 387-399

Ryan, P. 2005. The market impact of directors trades: Relationship to various measures of a Firm's information environment. British Accounting Review 37, 319-337

Smith. C.M, and R.L Watts. 1992. The Investment Opportunity Set and Corporate Financing,Dividend and Compensation Policies. Journal of financial Economics. Vol. 32, pp 263292.

Stiles, P. and Taylor, B. 2001. Boards at work - how directors view their roles and responsibilities. Oxford University Press, Oxford.

Sudana.M. 2011. Manajemen Keuangan Perusahaan Teori dan Praktik. Jakarta: Penerbit Erlangga.

Weston J. Fred dan Eugene F. Brigham. 1998. Dasar dasar Manajemen Keuangan. Edisi kesembilan. Jilid 2. Terjemahan. Jakarta : Penerbit Erlangga

Wijaya D. 2008. Pengaruh Rasio Modal Saham terhadap Return Saham Perusahaan-Perusahaan Telekomunikasi Go Public di Indonesia Periode 2007.

Yermack, D. 1996. Higher market valuations of companies with a small board of directors. Journal of Financial Economics 40, 185-211.

Yawson, A. 2006. Evaluating the characteristics of corporate boards associated with layoff Decision. Corporate Governance: An International Review 14(2), 75-84

maupun perusahaan kecil. 
Brayen Prastika DwiPutra 